\title{
The Impact of Women Cumulative Empowerment and Educational Gap on the Participation of Arabic Women in the Labor-Force
}

\author{
Hanan Atta Shamlawi \\ The University of Jordan, Business College, Business Economics Department, Amman, Jordan
}

Email address:

hanan0099@hotmail.com

\section{To cite this article:}

Hanan Atta Shamlawi. The Impact of Women Cumulative Empowerment and Educational Gap on the Participation of Arabic Women in the Labor-Force. International Journal of Business and Economics Research. Vol. 8, No. 5, 2019, pp. 263-272.

doi: $10.11648 /$ j.ijber.20190805.13

Received: June 13, 2019; Accepted: July 17, 2019; Published: August 6, 2019

\begin{abstract}
Woman is a key and an important contributor to development, therefore, enhancing her empowerment is a vital driver and a key element for a development process that is sustainable and continuous. Measuring the impact of both of cumulative woman empowerment, and educational empowerment (educational gap) on the participation of women in the labor force is crucial for pinpointing the fragility in woman empowerment efforts in the Arab region. This paper aims at investigating the impact of both women cumulative empowerment and educational gap on the participation of women in the labor force in the Arab countries. The study sample includes Arab countries that are included in the Global Gender Gap reports during the years (2006-2015). Using panel data, several econometrics models were estimated. Evidently, for the whole sample: both of women cumulative empowerment and the percentage of working women in the population have a significant positive impact on women's participation in the labor force, meanwhile there was a negative impact of the population growth rate, and a both ways impact - positive and negative- of educational gender gap. After dividing Arab countries according to income groups, it is found that, for both high-income and lower middle income countries, there is a positive significant impact for women empowerment on women's participation in the labor force. However, the results do not support any significant impact for women empowerment on women's participation in the labor force in the upper middle income countries. It was also found that the proportion of working women out of the population was statistically significant for the three income levels. Also the results do not support any significant impact for both of the educational gap and population growth on women's participation in the labor force.
\end{abstract}

Keywords: Women Empowerment, Women Participation Rate in Labor Force, Economics of Gender, Economic Development, Gender Gap

\section{Introduction}

One of the goals of sustainable development in the Arab countries is to increase the participation of women in the labor force and to increase their empowerment. In order to achieve this, there has been a growing interest in research on the factors that affect the contribution of women in the labor force. Economic theories have concluded that these factors can be divided into social factors, and economic factors, the most important of which are per capita income and educational level [5]. Increasing women's educational empowerment leads to increased their economic participation, on the other hand women's economic participation increases with: fertility decline [13], and the availability of employment saving technology [16]. There is a relationship between both of population growth, the increase in the proportion of women in the population structure and their rates of involvement in the labor market [16]. Also there are economic dimensions of demographic phenomena's, such as increasing the proportion of women among the population and participation in the labor force. At the present time, there is considerable interest in linking the concept of empowerment and the gender gap to the participation of women in the labor force, and increasing 
their economic participation. As the cumulative empowerment of women increases their participation in economic activity increases.

The subject of the contribution of women in the labor force has received widespread attention in economic literature. Studies have focused on one or more factors that affect the economic contribution of women, an important study has linked women empowerment and their economic contribution by Sultana [11], which emphasized the positive role of both education and women's economic participation using an econometrics model. Regarding the studies of the Arab countries, there is a study Abu Nahla, [1] which found that the participation rate of Arab women in the economy in the Arab countries and their participation in the labor force is lower than the global rate.

What distinguishes this study from the previous studies is that it has developed an econometrics model for estimating the contribution of Arab women in the labor force and linking this contribution to the cumulative empowerment of women. The study is based on international data issued by international economic institutions, thus covering a gap in the economic literature of the Arab region. Previous studies lack a comprehensive view of the subject of the participation of Arab women in the labor force. This paper examines the factors influencing the participation of women in the labor force in the Arab countries and more specifically aims to study the impact of women's empowerment on their participation in the labor force by building an econometrics model for assessing the impact of women's participation in the labor force in countries Arabic during the period (20062015). The first part covers the concept of women's empowerment and measurement, followed by a descriptive presentation of the facts about the gender gap and educational gap in the Arab countries in Part II, and then introducing an econometrics model to measure the impact of cumulative women empowerment and educational gap on women's participation in the workforce. In part III, finally comes the conclusion and recommendations.

\section{The Study Problem}

Arab women suffer from low participation in the labor force. It is very important to know the reasons for the decline in these participations and the factors affecting it. There are many factors that affect the participation of women in the labor force, such as the educational level, the percentage of women in the population, and the fertility rate. Some of other important factors that have not been discussed before, like the impact of women's cumulative empowerment and the gender gap on their participation in the labor force. A healthy, educational, economically and politically empowered woman is able to make her own decisions, thus increasing her enrollment in the labor force. Hence the problem of the study can be obviously shown by answering the following question:

Is there a statistically significant impact of the level of women's cumulative empowerment and the educational gap on women's participation in the labor force? and does this impact- if any- change as the level of income differ?

\section{The Study Hypotheses}

1. There is no statistically significant impact of the level of cumulative empowerment of women on the participation rate of women in the labor force.

2. There is no statistically significant impact of the educational gap on the participation rate of women in the labor force.

3. There is no statistically significant impact of the proportion of working women in the population on the participation of women in the labor force.

4. There is no statistically significant impact of population growth on the participation rate of women in the labor force.

\section{Community and Study Data}

Data used in this study was taken from publicly available resources, such as the Global Gender Gap Report, the annual World Economic Forum published surveys, and all survey reports from the general statistics in the countries under study. The study covers Arab countries included in the report of the gender gap during the years (2006-2015) which are Saudi Arabia, Qatar, Oman, Bahrain, UAE, Kuwait, Jordan, Egypt, Mauritania, Tunisia, Morocco, Lebanon, Yemen, Syria and Algeria.

\section{The Study Methodology}

The percentage of women's participation in the labor force has been chosen as a dependent variable of the study and the variable of women's empowerment was considered as an independent variable in order to estimate the impact of women empowerment on her participation in the labor force. To achieve this aim, a linear regression model of the time series data for the Arab countries has been formulated as follows:

$$
\text { FLPRit }=\beta 0+\beta 1 \text { CEIit }+\beta 2 \text { FEPRit }+\beta 3 \text { EDUit }+\beta 4 \text { PGRit }+ \text { Uit }
$$

$\mathrm{t}$ refers to time and $\mathrm{i}$ refers to the state, $\mathrm{U}$ refers to the random error in estimating the model. The dependent variable is the rate of participation of women in the labor force (FLPR), the explanatory variable is the Cumulative Indicator for the Empowerment of Women (CEI). Some variables have been added, which are related to the participation of women in the labor force such as Percentage of working women and population growth. The model was estimated at four levels (all countries, high-income countries, middle-income countries and low-income countries)

\section{The Concept of Women's Cumulative Empowerment and Its Measurement}

The empowerment of women is a multifaceted process, a 
potential variable, which cannot be observed and measured directly (Kabeer, 2003). Empirical research on women's empowerment has also shown that the concept of women's empowerment has problems in defining and measuring it (Swain, 2008).

According to the definition of ESCWA (2012), the process of empowering women is the process by which women become individually and collectively aware of the way that affects the relationships of power in their lives, gaining selfconfidence and strength in addressing, the inequality between them and men, the gender equality, and women empowerment are two terms that can be achieved by achieving the other. The gender gap is inversely proportional to empowerment, the less the gender gap, the greater the empowerment of women. The majority of recent studies on empowerment of women have concluded that the indicators of empowerment do not exceed four aspects: education, economic, health and politics.

\section{The Concept of Educational Empowerment}

Education is one of the most important pillars of women's empowerment. Achieving women's basic economic, social and political empowerment components depends on women's education. The lack of education of women makes their political and economic participation very difficult and even impossible. There is a wide disparity in the conditions of education between rural and urban areas, especially in developing countries, female enrollment is less in rural area than urban area due to traditions, customs and social beliefs, in rural areas, girls have a late priority in education due to early marriage or assistance. In some countries, female education is different from male education, because there are convictions that female education is aimed at "preparing good wives for married life". Another fact that one should not lose sight of is that there is a prevailing social tradition, which makes the women the first to be abounded from education, with its high costs. In the Gender Gap Report, educational empowerment is a general indicator included some sub-indicators such as literacy, enrollment in primary education, enrollment in secondary education, and enrollment in higher education (World Economic Forum, 2015).

Investing in human capital leads to increase the knowledge base of society and to increase the benefit from accumulated human capital, and then for achieve growth at all levels. By investment in education, it is important to reach to the achievement of the objectives of the national economy, As the educational system works to link its outputs with the needs and requirements of the development process. In general, education is associated with a number of socioeconomic indicators such as women's empowerment (Meshaal, Saruji, 2006). Women's education is particularly valued at the value of their time at work, which is positively reflected in higher wages, followed by an increase in the family income. Thus, women become an effective and capable element at the family level, at the level of society in which they live, and gain an added economic value.

Estimating returns from education is an important part of the literature of economic development and human capital. Many scholars have provided estimates of the returns of education in many countries in general, but studies of women's empowerment are still remarkably low, the relationship between the estimates of the return on education and the degree of economic development was discussed, emphasizing that accumulation of human capital is one of the most important engines of economic growth. Man, is dominant and directed towards physical capital, development cannot succeed without human intellectual content. Linking between return on education and women empowerment needs a survey data which unfortunately did not exist for Arab countries so we will depend on destructive analysis of the results that attempted to link the return on education by empowering women by estimating the return on education in Jordan and the Arab countries and showing the impact of the return on education for both male and female, and to indicate whether there is a difference in the return on education due to sex, and to clarify the impact of the return on education on women's empowerment. It is important to talk about empowering women to try to answer whether there is a difference in return on education due to gender, the return on education is empowering upon the woman.

There are some constants with regard to the return on education. The theory of human capital is the basis of the concept of return on education. It is established that what one gets is always more than the money spent (Walsh, 1935). The return on investment in education is higher than the return on education Investment in other sectors (Psacharopoulos 1985), and that the return on education increases with the increase in educational level (Silles, 2007). The return on female education is higher than the return on male education. The difference in the average return of the sexes is $1 \%$ for female benefit (Psacharopoulos 2002).

For the countries under study, the Arab Institute for Studies and Research (2009) conducted a country study of a sample of Arab countries under study, including Jordan, Kuwait, Morocco, Mauritania, Yemen and Oman, by applying the (Mainster, indicator). the study in particular, showed:

1. The Arab countries are different in style from the international patterns monitoring of rates of return on education, which is low overall rate of return on education in general but it has a rising tendency as income and education levels increases.

2. The rate of return on education in the Arab countries reaches $(7.3 \%)$, which is low compared with: the world rate $(9.7 \%)$, the low-income countries rate $(10.9 \%)$, and the middle-income countries rate $(10.7 \%)$, but it is almost equal to the world's high-income countries rate which is $(7.4 \%)$.

3. Higher rate of return on education in the Arab countries, combines with high income level, it reaches $(11.4 \%)$ in Kuwait, which is classified as a highincome country, and it reaches (5.5\%) in Jordan, which 
is classified among the high middle income countries, it reaches $(1.8 \%)$ In Yemen, which is classified as lowincome country.

4. The rate of return on female education was higher than that of males in all Arab countries. The rate of return on education for males and females in Kuwait was 12.3\% and $14.7 \%$ respectively. And it had reaches its least in Yemen as it was for Males, and females (1.8\%) and $(2.3 \%)$ respectively, while in Jordan it was $5.7 \%$ for males and $7.5 \%$ for females.

5. The rate of return on education for males in the Arab countries was $(7.1 \%)$ which is less than in the world countries $(8.7 \%)$. As well as the rate of return on education for females in the Arab countries, which amounted to $(9.3 \%)$ compared with the world countries. $(9.8 \%)$.

Out of all the previously mentioned Studies, it is shown that women's education has a positive impact on their economic activity, their type of savings, the type of job they have, and the level of their income (Meshaal, Saruji, 2007). Moreover, there is a direct relationship between the volume of expenditure on education and economic growth. Thus, the increase in education leads to increasing the economic empowerment of women on the one hand and on the other hand is linked by increasing economic growth, which benefit the society as a whole leading to sustainable development. It is possible to say that the return on education in the Arab countries in general, is revolve to the world pattern and the theory of human capital, it can be characterized by a low overall rate of return on education with a tendency to rise as income and education levels rise and there are differences in the return on education due to gender differs.

\section{Facts About Bridging the General Gender Gap and the Educational Gap in Arab Countries}

The economies of the Arab countries which covered by the Gender Gap Report are heterogeneous. This heterogeneity has been reflected in the average per capita income of the population. So It can be divided into three groups according to per capita income, first, low-middle income countries with annual average per capita income of (4125-1046) US \$, this group includes: Egypt, Mauritania, Morocco, Syria, Yemen. Second group high-middle income countries with an annual per capita income of US \$4,126-12735, and this group consist of Algeria, Jordan, Lebanon and Tunisia. And finally high-income countries with an annual per capita income of US \$ 12735. These include: Gulf Arab states: Kuwait, UAE, Qatar, Bahrain, Saudi Arabia and Oman. Through the 2015 Gender Gap Report the Arab countries under study are experiencing a low level of economic participation. The worst performance has been reflected in three gaps: the participation gap (the difference in the labor force participation rate between men and women) and the progress gap (the ratio of women to men within Class legislators, senior employees, managers, professional and skilled workers), and the wage gap. According to the Gender Gap Report the worst-performing countries in both the percentage of women's participation in the labor force and in the income indicators obtained by women in ascending order are: Syria, Saudi Arabia, Yemen, Algeria, Morocco, Oman and Jordan.

The Gender Report was first published in 2006 to determine a gender equality measure, and to track the development of countries' classification over time, and with the publication of the Gender Gap Report (2015), data were available for approximately 10 years, that means a decade, The enables us to shed the light on the extent of the development of the Arab countries regarding gender equity and thus increased women's empowerment (World Economic Forum, 2006-2015).

The Arab situation in the area of bridging the gender gap and the educational gap can be analyzed and compared with the global achievement by reference to tables 1-2. An analysis of these tables reveals the development of Arab performance in the field of bridging the gender gap within a decade 2006-2015), and a general conclusion can be reached, that most of the Arab countries on the list have achieved important achievements which goes along with the global levels in bridging the gap in education and health, however many Arab countries have made achievements which are less than the global one regarding economic and political participations, In other words, the success of the Arab countries in the areas of education and health is threatened by economic and political failure.

The Arab region has been ranked late in the international rankings, although it has succeeded in reducing the overall gender gap by $60 \%$. However, in the area of sub-indices, it has succeeded in reducing the economic participation gap by only $43 \%$. The gender gap in terms of education has been reduced by $94 \%$, but no country in the region has succeeded in closing the gender gap completely.

Table 1. General Gender Gap Index for Arab Countries during (2006-2015).

\begin{tabular}{|c|c|c|c|c|c|c|c|c|c|c|c|c|c|c|c|c|c|c|c|c|}
\hline \multirow{2}{*}{ Country } & \multicolumn{2}{|l|}{2006} & \multicolumn{2}{|l|}{2007} & 2008 & \multicolumn{2}{|r|}{2009} & \multicolumn{2}{|r|}{2010} & \multicolumn{2}{|r|}{2011} & \multicolumn{2}{|r|}{2012} & \multicolumn{2}{|r|}{2013} & \multicolumn{2}{|r|}{2014} & \multicolumn{3}{|c|}{2015} \\
\hline & Index & Rank & Index & Rank & Index & Rank & Index & Rank & Index & Rank & Index & Rank & Index & Rank & Index & Rank & Index & Rank & Index & Rank \\
\hline No. of countries & & 114 & & 128 & & 130 & & 134 & & 134 & & 135 & & 135 & & 136 & & 142 & & 145 \\
\hline \multicolumn{21}{|c|}{ Lower Middle Income Countries Group } \\
\hline Egypt & $57.9 \%$ & 109 & $58.1 \%$ & 120 & $58.3 \%$ & 124 & $58.6 \%$ & 126 & $59.0 \%$ & 125 & $59.3 \%$ & 123 & $59.7 \%$ & 126 & $59.4 \%$ & 125 & $60.6 \%$ & 129 & $59.9 \%$ & 136 \\
\hline Mauritania & $58.3 \%$ & 106 & $60.2 \%$ & 111 & $61.2 \%$ & 110 & $61.0 \%$ & 119 & $61.5 \%$ & 113 & $61.6 \%$ & 114 & $61.3 \%$ & 119 & $58.1 \%$ & 132 & $60.3 \%$ & 131 & $61.3 \%$ & 132 \\
\hline Morocco & $58.3 \%$ & 107 & $58.8 \%$ & 122 & $57.6 \%$ & 125 & $59.3 \%$ & 124 & $57.7 \%$ & 127 & $58.0 \%$ & 129 & $58.3 \%$ & 129 & $58.5 \%$ & 129 & $59.9 \%$ & 133 & $59.3 \%$ & 139 \\
\hline Syria & N/A & N/A & $62.2 \%$ & 103 & $61 \%$ & 107 & $60 \%$ & 121 & $59.3 \%$ & 124 & $59.0 \%$ & 124 & $56.3 \%$ & 132 & $56.6 \%$ & 133 & $57.7 \%$ & 139 & $56.8 \%$ & 143 \\
\hline
\end{tabular}




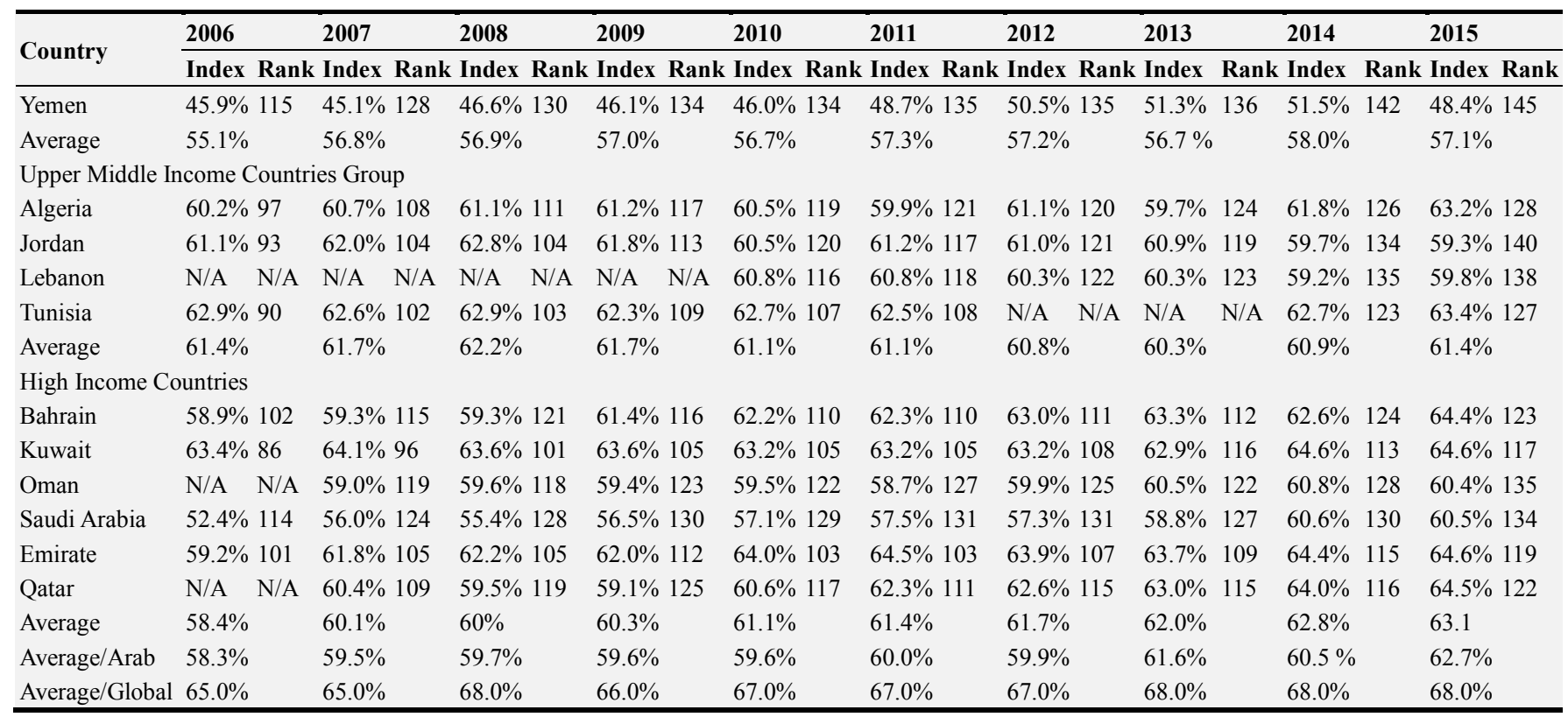

* The averages were calculated by researcher, Source: Gender Gap Report for years 2006 - 2015.

Table 2. Educational Attainment Gender Gap Index for Arab Countries during (2006-2015).

\begin{tabular}{|c|c|c|c|c|c|c|c|c|c|c|c|c|c|c|c|c|c|c|c|c|}
\hline \multirow{2}{*}{ Country } & \multicolumn{2}{|l|}{2006} & \multicolumn{2}{|l|}{2007} & \multicolumn{2}{|l|}{2008} & \multicolumn{2}{|l|}{2009} & \multicolumn{2}{|l|}{2010} & \multicolumn{2}{|l|}{2011} & \multicolumn{2}{|l|}{2012} & \multicolumn{2}{|l|}{2013} & \multicolumn{2}{|l|}{2014} & \multicolumn{2}{|l|}{2015} \\
\hline & Index & Rank & Index & Rank & Index & Rank & Index & Rank & Index & Rank & Index & Rank & Index & Rank & Index & Rank & Index & Rank & Index & Rank \\
\hline $\begin{array}{l}\text { No. of } \\
\text { countries }\end{array}$ & & 114 & & 128 & & 130 & & 134 & & 134 & & 135 & & 136 & & 136 & & 142 & & 145 \\
\hline \multicolumn{21}{|c|}{ Lower Middle Income Countries Group } \\
\hline Egypt & $90.3 \%$ & 90 & $90.9 \%$ & 101 & $90.2 \%$ & 105 & $90.0 \%$ & 107 & $89.9 \%$ & 110 & $90.8 \%$ & 110 & $92.5 \%$ & 110 & $92.0 \%$ & 108 & $94.7 \%$ & 109 & $93.5 \%$ & 115 \\
\hline Mauritania & $81.8 \%$ & 103 & $83.2 \%$ & 114 & $85.6 \%$ & 113 & $84.9 \%$ & 120 & $85.3 \%$ & 118 & $86.0 \%$ & 117 & $85.7 \%$ & 119 & $85.9 \%$ & 119 & $83.1 \%$ & 130 & $83.9 \%$ & 132 \\
\hline Morocco & $84.8 \%$ & 99 & $84.5 \%$ & 113 & $84.4 \%$ & 117 & $85.6 \%$ & 118 & $86.1 \%$ & 116 & $86.5 \%$ & 115 & $87.4 \%$ & 115 & $90.0 \%$ & 109 & $91.9 \%$ & 116 & $91.4 \%$ & 123 \\
\hline Syria & N/A & N/A & $92.7 \%$ & 99 & $92.7 \%$ & 101 & $93.1 \%$ & 104 & $93.6 \%$ & 104 & $91.4 \%$ & 109 & $93.1 \%$ & 107 & $96.8 \%$ & 96 & $96.7 \%$ & 101 & $96.5 \%$ & 103 \\
\hline Yemen & $59.8 \%$ & 114 & $56.5 \%$ & 127 & $61.8 \%$ & 129 & $61.5 \%$ & 133 & $65.7 \%$ & 132 & $64.2 \%$ & 134 & $68.4 \%$ & 133 & $69.8 \%$ & 134 & $70.7 \%$ & 140 & $72.0 \%$ & 142 \\
\hline Average & $79.1 \%$ & & $81.5 \%$ & & $82.9 \%$ & & $83.2 \%$ & & $84.1 \%$ & & $83.7 \%$ & & $85.4 \%$ & & $86.9 \%$ & & $87.4 \%$ & & $87.4 \%$ & \\
\hline \multicolumn{21}{|c|}{ Upper Middle Income Countries Group } \\
\hline Algeria & $94.4 \%$ & 84 & $94.2 \%$ & 96 & $94.9 \%$ & 96 & $95.1 \%$ & 99 & $95.3 \%$ & 99 & $95.0 \%$ & 96 & $95.0 \%$ & 103 & $93.9 \%$ & 106 & $93.6 \%$ & 113 & $94.6 \%$ & 110 \\
\hline Jordan & $97.9 \%$ & 70 & $97.9 \%$ & 79 & $98.6 \%$ & 80 & $98.5 \%$ & 83 & $98.7 \%$ & 81 & $98.7 \%$ & 79 & $98.6 \%$ & 82 & $99.2 \%$ & 68 & $99.1 \%$ & 74 & $98.3 \%$ & 93 \\
\hline Lebanon & N/A & N/A & N/A & N/A & N/A & N/A & N/A & N/A & $97.7 \%$ & 91 & $97.7 \%$ & 90 & $98.0 \%$ & 86 & $98.0 \%$ & 87 & $95.2 \%$ & 106 & $96.3 \%$ & 104 \\
\hline Tunisia & $95.9 \%$ & 77 & $95.9 \%$ & 88 & $96.2 \%$ & 93 & $96.1 \%$ & 97 & $96.6 \%$ & 94 & $96.6 \%$ & 94 & N/A & N/A & N/A & N/A & $95.1 \%$ & 107 & $95.3 \%$ & 107 \\
\hline Average & $96 \%$ & & $96 \%$ & & $96.5 \%$ & & $96.5 \%$ & & $97 \%$ & & $97.0 \%$ & & $97.2 \%$ & & $97 \%$ & & $95.7 \%$ & & $96.1 \%$ & \\
\hline \multicolumn{21}{|c|}{ High Income Countries } \\
\hline Bahrain & $98.9 \%$ & 54 & $98.9 \%$ & 59 & $99.2 \%$ & 66 & $99.1 \%$ & 69 & $99.1 \%$ & 60 & $98.6 \%$ & 81 & $99.5 \%$ & 47 & $99.1 \%$ & 71 & $98.6 \%$ & 90 & $98.1 \%$ & 94 \\
\hline Kuwait & $99.3 \%$ & 41 & $98.9 \%$ & 63 & $99.0 \%$ & 74 & $98.1 \%$ & 86 & $98.6 \%$ & 83 & $98.3 \%$ & 84 & $99.4 \%$ & 60 & $99.4 \%$ & 57 & $99.1 \%$ & 76 & $99.1 \%$ & 77 \\
\hline Oman & N/A & N/A & $97.1 \%$ & 83 & $97.4 \%$ & 89 & $97.4 \%$ & 93 & $97.8 \%$ & 90 & $94.1 \%$ & 99 & $96.8 \%$ & 96 & $97.4 \%$ & 94 & $97.4 \%$ & 96 & $98.4 \%$ & 92 \\
\hline Saudi Arabia & $88.0 \%$ & 93 & $96.1 \%$ & 87 & $97.9 \%$ & 85 & $97.5 \%$ & 92 & $97.4 \%$ & 92 & $96.7 \%$ & 92 & $97.6 \%$ & 91 & $97.6 \%$ & 90 & $98.7 \%$ & 86 & $98.8 \%$ & 82 \\
\hline Emirate & $98.6 \%$ & 61 & $98.7 \%$ & 68 & $99.6 \%$ & 46 & $99.2 \%$ & 67 & $99.8 \%$ & 37 & $99.1 \%$ & 59 & $100.0 \%$ & 1 & $100.0 \%$ & 1 & $98.8 \%$ & 83 & $98.7 \%$ & 86 \\
\hline Qatar & N/A & N/A & $99.3 \%$ & 45 & $99.7 \%$ & 41 & $99.5 \%$ & 53 & $98.9 \%$ & 74 & $99.2 \%$ & 57 & $99.8 \%$ & 36 & $99.4 \%$ & 53 & $97.5 \%$ & 94 & $97.7 \%$ & 96 \\
\hline Average & $96.2 \%$ & & $98.2 \%$ & & $98.8 \%$ & & $98.5 \%$ & & $98.6 \%$ & & $97.6 \%$ & & $98.9 \%$ & & $98.8 \%$ & & $98.4 \%$ & & $98.5 \%$ & \\
\hline $\begin{array}{l}\text { Average/ } \\
\text { Arab }\end{array}$ & $90.4 \%$ & & $91.9 \%$ & & $92.7 \%$ & & $92.7 \%$ & & $93.4 \%$ & & $92.8 \%$ & & $93.8 \%$ & & $94.2 \%$ & & $94.0 \%$ & & $94 \%$ & \\
\hline $\begin{array}{l}\text { Average/ } \\
\text { Global }\end{array}$ & $92.0 \%$ & & $92.0 \%$ & & $95.0 \%$ & & $93.0 \%$ & & $93.0 \%$ & & $93.0 \%$ & & $93.0 \%$ & & $93.0 \%$ & & $94.0 \%$ & & $95.0 \%$ & \\
\hline
\end{tabular}

* The averages were calculated by researcher, Source: Gender Gap Report for years 2006 - 2015

It is noticeable that there is a clear correlation between the increased empowerment resulting from the reduction of the gender gap and the level of income. High-income countries recorded a significant achievement in bridging the gender gap, as evidenced by improvements in both their general indicators and education indicators. The reason for this good achievement refers to the right employment of female energies or capacities in society, which has increased the competitiveness of these communities, the value of the indicator increases in rich countries that give greater 
opportunities, to all members of society.

\section{Estimating the Econometrics Model of the Impact of Women's Empowerment on Their Participation in the Labor Force}

The time series data for the study sample, which includes a group of 15 Arab countries, was used to estimate the relationship between women's empowerment and their participation in the workforce over the years 2006-2015.

\subsection{Define the Model Variables}

These definitions include a description of the variables used in the econometrics analysis, the dependent variable is the ratio of women's participation in the labor force (FLPR), and the explanatory variable is the cumulative indicator of women's empowerment (CEI). Other independent variables of the model are: the percentage of working women as a portion of whole population (FEPR), the educational gap for women (EDU), and the population growth rate (PGR).

These variables are measured as follows:

1. Participation rate of women in the labor force (FLPR): It is the dependent variable.

2. The Cumulative Indicator for the Empowerment of Women (CEI) is an independent variable. It is measured by the rate of bridging the cumulative gender gap between males and females, which is the weighted average of four sub-indicators, including: the economic empowerment index, the educational empowerment index, the political index, And the Health Empowerment Index, all are taken from the Gender Gap Reports 2006-2015. After calculating the total gender gap, the final value of the index becomes between (1-0), (1) indicates full equality and closure of the gender gap and thus full empowerment of women. The figure $(0)$ indicates gender inequality and a complete gap. Not empowering women.

The control variables are:

The educational empowerment of women (EDU), it is expressed as a percent, and was calculated by taking the weighted mean of LR, PE, SE, TE.

1. (LR) Ratio of women to men in terms of literacy: It is the proportion of the population aged 15 and over who read and write and have the ability to understand the terms.

2. (PE) Ratio of women to men in terms of the number of persons enrolled in primary education: The total number of students enrolled in primary education who are supposed to be at the appropriate age for this level.

3. (SE) Ratio of women to men in terms of the number of students enrolled in secondary education: This is the total number of students of the appropriate age for this stage who are actually enrolled in this school stage and expressed for the population in the same age group.
4. (TE) Ratio of women to men in terms of enrollment in tertiary education: The total number of students enrolled in tertiary education regardless of age.

5. The proportion of working women in the total population (FPR): the total number of working women to the total population, this data is taken from the reports of (Statistical Economic and Social Research and Training Center for Islamic Countries) (SESRIC) for the years 2006-2015.

6. Population growth rate (PGR): Data were obtained based on the Statistical Economic and Social Research and Training Center for Islamic Countries (SESRIC) reports for the years (2006-2015).

\subsection{The Econometrics Model}

In this part of the study, the impact of women cumulative empowerment and educational gap on women's participation in the labor force was estimated during the years 2006-2015 using time series data for the study sample.

\subsubsection{Procedural Definitions}

(The procedural definitions include a description of the variables used in the standard analysis. The dependent variable in this section is the ratio of women's participation in the labor force (FLPR). The explanatory variable is the cumulative indicator of women's empowerment (CEI). Some control variables which are related to women, have been added. These variables are percentage of working women of the total population (FEPR), percentage of bridging the educational)

The procedural definitions include a description of the variables used in the standard analysis. The dependent variable in this section is the ratio of women's participation in the labor force (FLPR). The explanatory variable is the cumulative indicator of women's empowerment (CEI). Other variables which are related to women have been added. These variables are: percentage of working women of the total population (FEPR), percentage of bridging the educational gender gap for women (EDU) and population growth rate (PGR).

It is expected that there will be a positive correlation between the independent variables and the dependent variable, with the exception of the population growth variable. It is expected that the relationship between this variable and the dependent variable will be reversed if the percentage of women who are considered outside the labor force is higher than the population. The variable ratio of working women in the population can be expected to have a direct impact on the participation of women in the labor force. As is the case with the empowerment variable for women, the increase in women's empowerment is an indicator of increased economic participation of women.

\subsubsection{Test Model}

In this part of the study, the impact of women's empowerment on the participation of women in the labor force will be analyzed to determine the direction and 
significance of the relationship between explanatory and dependent variables. To this end, the linear regression model for the following time series data was developed:

$$
\text { FLPRit }=\beta 0+\beta 1 \text { CEIit }+\beta 2 \text { FEPRit }+\beta 3 \text { EDUit }+\beta 4 \text { PGRit }+ \text { Uit }
$$

$\mathrm{t}$ refers to the time and i refers to the state, and $\mathrm{U}$ indicates the random error in the estimation of the model. The model will be tested on four levels (all countries, high-income countries, upper middle-income countries and lower middle income countries), as previously classified.

\subsubsection{Statistical Tests of the Study Variables}

The reliability of the results of the standard analysis is based on testing the statistical characteristics of the variables of the study model. To obtain an estimate that has the desired characteristics of the model, it is necessary to ensure that there are no statistical problems associated with the model variables. some statistical tests can be used for the study variables to help in obtaining a desirable estimate. After testing the unit root for data stability, the results were as follows:

Table 3. Unit root test results for data stability.

\begin{tabular}{llll}
\hline High-income countries & & & \\
\hline Variable & t-statistic & Probability & Stationary Level \\
\hline FLPR & 4.646 & $0.000^{*}$ & $1^{\text {st }}$ difference $^{2}$ \\
CEI & -3.322 & $0.000^{*}$ & $1^{\text {st }}$ difference $^{2}$ \\
FEPR & 2.965 & $0.001^{*}$ & $1^{\text {st }}$ difference $^{2}$ \\
EDU & -7.423 & $0.000^{*}$ & $1^{\text {st }^{2}}$ difference $^{2}$ \\
PGR & -3.522 & $0.000^{*}$ & $1^{\text {st }^{2}}$ difference $^{2}$ \\
\hline
\end{tabular}

\begin{tabular}{llll}
\hline All countries & & & \\
\hline Variable & t-statistic & Probability & Stationary Level \\
\hline FLPR & 3.872 & $0.000^{*}$ & $1^{\text {st }}$ difference $^{2}$ \\
CEI & 2.276 & $0.000^{*}$ & $1^{\text {st }}$ difference $^{2}$ \\
FEPR & 4.039 & $0.000^{*}$ & $1^{\text {st }}$ difference $^{2}$ \\
EDU & -4.901 & $0.000^{*}$ & $1^{\text {st }}$ difference \\
PGR & -4.463 & $0.000^{*}$ & $1^{\text {st }}$ difference $^{2}$ \\
\hline
\end{tabular}

\begin{tabular}{llll}
\hline Lower middle income countries & & & \\
\hline Variable & t-statistic & Probability & Stationary Level \\
\hline FLPR & 2.966 & $0.001^{*}$ & $1^{\text {st }}$ difference $^{3}$ \\
CEI & 4.364 & $0.000^{*}$ & $1^{\text {st }}$ difference $^{3}$ \\
FEPR & 4.802 & $0.000^{*}$ & $1^{\text {st }}$ difference $^{3}$ \\
EDU & -3.412 & $0.000^{*}$ & $1^{\text {st }}$ difference \\
PGR & -2.136 & $0.016^{*}$ & $1^{\text {st }}$ difference $^{3}$ \\
\hline
\end{tabular}

\begin{tabular}{llll}
\hline upper middle income countries & & & \\
\hline Variable & t-statistic & Probability & Stationary Level \\
\hline FLPR & 1.985 & $0.023^{*}$ & $1^{\text {st }}$ difference \\
CEI & 3.496 & $0.001^{*}$ & $1^{\text {st }}$ difference $^{3}$ \\
FEPR & 3.058 & $0.001^{*}$ & $1^{\text {st }}$ difference \\
EDU & -5.387 & $0.000^{*}$ & $1^{\text {st }}$ difference $^{3}$ \\
PGR & -2.251 & $0.012^{*}$ & $1^{\text {st }}$ difference $^{3}$ \\
\hline
\end{tabular}

The results of the stability test indicated that all the variables are unstable at the level, and therefore can stabilize after calculating the first difference. In this study, the standard models will be tested using the First Difference formula and an estimate can be obtained with the desired characteristics. After conducting a (multiclinearity test) between the explanatory variables using the Spearman test, the results were as shown in the following table. The results indicate that there is no linear correlation problem between the independent variables of the model.

Table 4. Spearman results for linear correlation.

\begin{tabular}{|c|c|c|c|c|}
\hline \multicolumn{5}{|c|}{ High-income countries } \\
\hline Correlation & D(CEI) & D(FEPR) & D(EDU) & D(PGR) \\
\hline & 1 & & & \\
\hline $\mathrm{D}(\mathrm{CEI})$ & -- & & & \\
\hline D(FEPR) & 0.059 & 1 & & \\
\hline
\end{tabular}




\begin{tabular}{|c|c|c|c|c|}
\hline \multicolumn{5}{|c|}{ High-income countries } \\
\hline \multirow{6}{*}{$\mathrm{D}(\mathrm{EDU})$} & D(CEI) & D(FEPR) & D(EDU) & D(PGR) \\
\hline & $\begin{array}{l}{[0.431]} \\
(0.667)\end{array}$ & -- & & \\
\hline & $\begin{array}{l}(0.667) \\
0.211\end{array}$ & 0.079 & 1 & \\
\hline & {$[1.563]$} & {$[0.573]$} & -- & \\
\hline & $(0.124)$ & $(0.568)$ & -- & \\
\hline & -0.082 & -0.217 & -0.119 & 1 \\
\hline \multirow[t]{2}{*}{$\mathrm{D}(\mathrm{PGR})$} & {$[-0.596]$} & {$[-1.607]$} & {$[-1.869]$} & -- \\
\hline & $(0.553)$ & $(0.114)$ & $(0.388)$ & -- \\
\hline \multicolumn{5}{|l|}{ All countries } \\
\hline \multirow[t]{2}{*}{ Correlation } & D(CEI) & D(FEPR) & D(EDU) & D(PGR) \\
\hline & 1 & & & \\
\hline \multirow[t]{2}{*}{$\mathrm{D}(\mathrm{CEI})$} & -- & & & \\
\hline & -- & & & \\
\hline \multirow{3}{*}{ D(FEPR) } & 0.066 & 1 & & \\
\hline & {$[0.774]$} & -- & & \\
\hline & $(0.440)$ & -- & & \\
\hline \multirow{3}{*}{$\mathrm{D}(\mathrm{EDU})$} & 0.165 & -0.034 & 1 & \\
\hline & [1.934] & {$[-0.397]$} & -- & \\
\hline & $(0.055)$ & $(0.691)$ & -- & \\
\hline \multirow{3}{*}{ D(PGR) } & -0.094 & -0.05 & -0.062 & 1 \\
\hline & {$[-1.097]$} & {$[-0.581]$} & {$[-0.722]$} & -- \\
\hline & $(0.274)$ & $(0.561)$ & $(0.471)$ & -- \\
\hline \multicolumn{5}{|c|}{ Lower middle income countries } \\
\hline \multirow[t]{2}{*}{ Correlation } & $\mathrm{D}(\mathrm{CEI})$ & D(FEPR) & D(EDU) & D(PGR) \\
\hline & 1 & & & \\
\hline \multirow[t]{2}{*}{$\mathrm{D}(\mathrm{CEI})$} & -- & & & \\
\hline & -- & & & \\
\hline \multirow{3}{*}{$\mathrm{D}(\mathrm{FEPR})$} & 0.223 & 1 & & \\
\hline & {$[1.501]$} & -- & & \\
\hline & $(0.140)$ & -- & & \\
\hline \multirow{3}{*}{$\mathrm{D}(\mathrm{EDU})$} & 0.13 & -0.063 & 1 & \\
\hline & {$[0.862]$} & {$[-0.420]$} & -- & \\
\hline & $(0.393)$ & $(0.676)$ & -- & \\
\hline \multirow{3}{*}{$\mathrm{D}(\mathrm{PGR})$} & -0.003 & -0.119 & -0.106 & 1 \\
\hline & {$[-0.024]$} & {$[-0.790]$} & {$[-0.704]$} & -- \\
\hline & $(0.980)$ & $(0.433)$ & $(0.485)$ & -- \\
\hline \multicolumn{5}{|c|}{ upper middle income countries } \\
\hline \multirow[t]{2}{*}{ Correlation } & D(CEI) & D(FEPR) & D(EDU) & D(PGR) \\
\hline & 1 & & & \\
\hline \multirow[t]{2}{*}{$\mathrm{D}(\mathrm{CEI})$} & -- & & & \\
\hline & -- & & & \\
\hline \multirow{3}{*}{ D(FEPR) } & -0.124 & 1 & & \\
\hline & {$[-0.733]$} & -- & & \\
\hline & $(0.468)$ & -- & & \\
\hline \multirow{3}{*}{$\mathrm{D}(\mathrm{EDU})$} & 0.278 & -0.01 & 1 & \\
\hline & [1.689] & {$[-0.059]$} & -- & \\
\hline & $(0.100)$ & $(0.953)$ & -- & \\
\hline \multirow{3}{*}{$\mathrm{D}(\mathrm{PGR})$} & -0.015 & 0.18 & 0.077 & 1 \\
\hline & {$[-0.091]$} & {$[1.067]$} & {$[0.455]$} & -- \\
\hline & $(0.927)$ & $(0.293)$ & $(0.651)$ & -- \\
\hline
\end{tabular}

\subsubsection{Standard Model Estimation Results}

After confirming that there were no statistical problems in the estimated model data for the study, the model was tested using the First Difference (FD) formula, and the results were as shown in the following table. 
Table 5. Results of the assessment of the model of participation of women in the labor force.

\begin{tabular}{lllll}
\hline \multicolumn{2}{l}{ Variable female participation in DFLPR workforce } & & \\
\hline \multirow{2}{*}{ Coefficients } & All countries & High-income countries & upper middle income countries & Lower middle income countries \\
\cline { 2 - 5 } & Random Effects & Random Effects & Fixed Effects ${ }^{\wedge}$ & Random Effects \\
\hline Probability of Hausman Test & 0.07 & 0.26 & NA & 0.07 \\
& $0.11^{*}$ & -0.004 & 0.13 & $0.10^{*}$ \\
Constant & {$[2.93]$} & {$[0.05]$} & {$[1.69]$} & {$[0.65]$} \\
& $(0.00)$ & $(0.95)$ & $(0.10)$ & $0.01)$ \\
& $0.07^{*}$ & $0.12^{* *}$ & 0.05 & $0.04^{* *}$ \\
DCEI & {$[2.23]$} & {$[1.90]$} & {$[0.71]$} & {$[.87]$} \\
& $(0.02)$ & $(0.06)$ & $(0.47)$ & $(0.06)$ \\
DFEPR & $0.64^{*}$ & $0.61^{*}$ & $0.60^{*}$ & $0.54^{*}$ \\
& {$[11.99]$} & {$[7.35]$} & {$[4.04]$} & {$[.94]$} \\
DEDU & $(0.00)$ & $(0.00)$ & $(0.00)$ & $(0.00)$ \\
& 0.000007 & -0.05 & -0.003 & 0.01 \\
DPGR & {$[0.22]$} & {$[-1.28]$} & {$[-0.03]$} & {$[0.63]$} \\
& $(0.82)$ & $(0.20)$ & $(0.97)$ & $(0.53)$ \\
R & -0.41 & -4.04 & -0.37 & -1.05 \\
F-Statistic & {$[-0.43]$} & {$[-1.57]$} & {$[-0.16]$} & {$[-0.60]$} \\
D.W & $(0.66)$ & $(0.12)$ & $(0.87)$ & $(0.54)$ \\
No. of Observation & 0.54 & 0.61 & 0.41 & 0.62 \\
\end{tabular}

() refers to $P$ value

[ ] refers to $t$ value

refers to significance at level $(5 \%, 1 \%)$ respectively. $*_{-} * *$

$\wedge$ refers to inability of using RE so FE used instead

From all of above the estimation results for all level countries, indicated a positive correlation between the explanatory variables (DCEI, DFEPR) and the dependent variable, and an inverse relationship between the explanatory variable (DPGR) and the dependent variable. A variable (DEDU) has an effect in both directions (positive and negative) on the dependent variable.

In terms of the estimated parameters of the model, the cumulative empowerment coefficient for women was $7 \%$, $12 \%, 5 \%$ and $4 \%$, respectively. The statistic of this parameter indicated a statistical significance of $5 \%$ at the level of all countries, and the presence of statistical significance at a significant level of $10 \%$ in high-income countries, and lower middle-income countries, which means that increasing women's cumulative empowerment by $1 \%$ leads to a direct increase in the participation of women in the labor force by $7 \%, 12 \%$ and $4 \%$, respectively. In the upper middle income countries, the results showed that there is no statistical indication of the cumulative empowerment of women on their participation in the labor force. Thus, this variable is statistically acceptable in explaining the variable of women's participation in the labor force (at the level of all countries, high-income countries and lower middle income countries). This indicates the importance of women's cumulative empowerment index to influence women's participation in the labor force, especially in high-income countries.

The percentage of working women in the population as a control variable was $64 \%, 61 \%, 60 \%$ and $54 \%$, respectively. The statistic (t-Statistic) indicated a statistical significance of $1 \%$ Labor force at the four income levels, which means that increasing the change in the proportion of working women in the population by $1 \%$, will lead to a change in the direct participation of women in the workforce by $64 \%, 61 \%, 60 \%$, $54 \%$ respectively.

The indicator of the percentage of educational gap indicated that this variable is not important in explaining the participation of women in the labor force at the four levels of income. The statistic (t-Statistic) indicates that there is no statistical significance for this variable on the participation of women in the labor force. As is the case for the population growth parameter.

The value of the R2 was the explanatory variables' ability to interpret differences in the dependent variable, where they were equal to $54 \%, 61 \%, 41 \%$ and $62 \%$, respectively. The $\mathrm{F}$ statistic indicated that there was statistical significance for the study models except for the model of high-income countries. The value of the F-test was low. Finally, the DW test indicates that there is no problem of self-correlation in the model. The statistic for this test lies between the highest value and the lowest value $(\mathrm{dU}=2.5>\mathrm{d}>\mathrm{dL}=1.5)$ Women's participation in the labor force using the cumulative empowerment index for women.

\section{Conclusion and Recommendations}

According to the standard model used the study showed that the impact of women's empowerment on their participation in the labor force varies among countries by income groups, In the high-income countries group, increasing cumulative empowerment of women through their health, educational and political support, leads to increase their participation in the labor force, the study also showed that at the level of all countries, 
both the cumulative empowerment index and the percentage of working women in the population had a positive and significant impact on the women participation in the labor force, and that there is a negative impact of the rate of population growth, and a both ways impact - positive and negative- of educational gender gap. After dividing Arab countries according to income groups, it is found that, for both high-income and lower middle income countries, there is a positive significant impact for women empowerment on women's participation in the labor force. However, the results do not support any significant impact for women empowerment on women's participation in the labor force in the upper middle income countries. It was also found that the proportion of working women out of the population was statistically significant for the three income levels. Also the results do not support any significant impact for both of the educational gap and population growth on women's participation in the labor force.

In the light of the results achieved and noting the positive correlation of women empowerment with the participation of women in the labor force at the level of all countries, it is very important to benefit from the disabled women's energies noting that about half the population in most of the sample countries are women. Increasing women participation in the labor force increases the productivity of society, which helps to achieve sustainable development and growth for all sectors. Hence, the researcher recommends working to improve the participation of Arab women in the labor force to approach the global average. Improving the participation of Arab Women in the labor force requires many policies and procedures, to enhance their economic participation and empowerment. These policies include, but are not limited to:

1. To provide a positive environment for women's work and to amend labor legislation and laws to include explicit provisions prohibiting discrimination between men and women in pay for similar work and criminalizing gender discrimination in the work environment.

2. At the national level, the most resources and efforts should be directed towards supporting any development projects for women that are lacking in the local markets and can be financed through microfinance institutions such as the production kitchen and all training and rehabilitation projects that increase women's productivity and facilitate women's access on loans, awareness-raising campaigns and a broad media base to promote and market women's projects.

3. Establish communication networks and build a sophisticated information base to allow women to learn about available investment opportunities and available financial resources.

\section{References}

[1] Abu Nahla, Lamis, 2005, Arab Women's Participation in Economic Activity and its Revenues, Women's Studies, Bir Zeit University, Palestine.
[2] Abdelkader Ali, 2009, Rate of Return on Education, Arab Institute for Studies and Research, Kuwait.

[3] Assaad, A, 2012, Gender and the Jordanian Labor Market, Economic Research Forum http: //www.erf.org.eg/cms.php? $\mathrm{Id}=$ publication_details \& publication_id $=1556$.

[4] Bandiera, O. and A. Natraj, 2013, Does Gender Inequality Hinder Development, World Bank.

[5] Duflo, E., 2012, Women Empowerment and Economic Development, Journal of Economic Literature, Vol. 50, No.4.

[6] ESCWA, 2012. Addressing the barriers to women's economic participation in the ESCWA region, Economic and Social Commission for Western Asia (ESCWA), New York: United Nations.

[7] Kabeer, Naila, 2003, Gender Mainstreaming in Poverty Eradication and the Millennum Development Goals, International Development Research Center (IDRC), Ottawa.

[8] Kabeer, Naila, 2005, Resources, Agency, Achievement: Refleactions on the measure of women empowerment, International Development Research Center (IDRC), Ottawa. Claire. 2013, Helpdesk Research Report: Women's economic role in the Middle East and North Africa (MENA), World Bank.

[9] Siller, Mary A, 2007, The Returns to Education for the United Kingdom, Journal of Economics, Vol X, No 2.

[10] Statistical Economic and social Reasearch and Training Center for Islamic Countries, SESRIC

http://www.sesrtcic.org/baseind-step1.php.

[11] Sultana, Hossen, 2013, Role of Employment in Women Empowerment: Evidence from Khulna City of Bangladesh, International Journal of Social Sciences \& Interdisciplinary Research, Vol. 9.

[12] Swain, Ranjula, Valentin, 2008, Economic and Non-Economic Factor What Empowers woman, Warking paper, UPPSALA University.

[13] Tasani, Stella, 2012, Female Labor Force Participation and Economic Development in Southern Mediterranean Countries: What Scenarios for 2030?, MEDPRO Technical Report No. 19, European Commission, European Research Area.

[14] World Economic Forum, 2006-2015, Gender Gap Report, Geneva, Switzerland:

http://www3.weforum.org/docs/WEFGenderGap_Report_.pd.

[15] World Bank, 2012-2015, World Development Indicators, Washington: World Bank.

[16] World Bank, 2012. Capabilities, Opportunities and Participation: Gender Equality and Development in the Middle East and North Africa Region, A companion to the World Development Report, 2012, Washington: World Bank.

[17] Zareen, Fand Naqvi, Lubna,, 2002, How Do Women Decide to Work in Pakistan? [with Comments], The Pakistan Development Review, Vol. 41, No. 4, Papers and Proceedings PART II Eighteenth Annual General Meeting and Conference of the Pakistan Society of Development Economists, Islamabad, 495-513. 